\title{
A UTILIZAÇÃO DE ELEMENTOS DA FLORESTA NA PRODUÇÃO DE RECURSOS METODOLÓGICOS PARA A O ENSINO DE CIÊNCIAS E MATEMÁTICA NO CONTEXTO AMAZÔNICO
}

\author{
THE USE OF FOREST ELEMENTS IN THE PRODUCTION OF \\ METHODOLOGICAL RESOURCES FOR TEACHING SCIENCE AND \\ MATHEMATICS IN THE AMAZON CONTEXT
}

\author{
José de Alcântara Filho ${ }^{1}$ \\ ORCID iD: 0000-0002-6337-7337 \\ Yuri Expósito Nicot ${ }^{2}$ \\ ORCID iD: $\underline{0000-0002-7114-0073}$
}

\begin{abstract}
RESUMO
Este artigo tem por finalidade apresentar uma possibilidade de aprendizagem consistente e socialmente significativa partindo da utilização dos recursos didáticos naturais. A pesquisa realizada mostra que o ensino pode ser dinâmico e participativo, possibilitando um conhecimento significativo dos conteúdos a ser ensinados. Mostramos a partir de um caso excepcional e criativo de um docente da rede estadual do município de Manaus que é possível transformar os elementos naturais em recursos metodológicos para ensinar Física e Matemática, desenvolvendo habilidades cognitivas no campo numérico e geométrico. Nessa pesquisa de cunho qualitativo, utilizamos entrevistas, observações e registros escritos e fotográficos. Concluímos que é possível a criação de recursos didático-metodológicos que favoreçam a região amazônica e os processos educativos. Este trabalho mostra que a floresta amazônica é rica em possibilidades e que seus recursos devem ser valorizados e utilizados na construção do conhecimento tendo em vista uma didática amazônica.
\end{abstract}

Palavras-chave: Recursos didáticos. Aprendizagem. Metodologias.

\begin{abstract}
This article aims to present a possibility of consistent and socially significant learning based on the use of natural didactic resources. The research carried out shows that teaching can be dynamic and participatory, allowing a significant knowledge of the contents to be taught. We show from an exceptional and creative case of a teacher from the state network of the municipality of Manaus that it is possible to transform natural elements into methodological resources to teach Physics and Mathematics, developing cognitive skills in the numerical and geometric fields. In this qualitative research, we used interviews, observations and written and photographic records. We conclude that it is possible to create didactic-methodological resources that favor the Amazon region and educational processes. This work shows that the Amazon forest is rich in possibilities and that its resources must be valued and used in the construction of knowledge in view of an Amazonian didactic.
\end{abstract}

\footnotetext{
${ }^{1}$ Mestre em Ensino de Ciências na Amazônia pela Universidade do Estado do Amazonas (UEA). Professor Assistente na Universidade do Estado do Amazonas (UEA), Manaus, Amazonas, Brasil. Av. Djalma Batista, 2470, Chapada, Manaus, Amazonas, Brasil, CEP: 69050-010. E-mail: jdfilho@uea.edu.br.

${ }^{2}$ Doutor em Educação pela Universidade Oriente (UO). Professor adjunto na Universidade Federal do Amazonas (UFAM), Manaus, Amazonas, Brasil. Av. General Rodrigo Otávio, 1200, Coroado, Manaus, Amazonas, Brasil, CEP: 69067-005. E-mail: yexposito@yahoo.es.
} 
Keywords: Didactic resources. Learning. Methodologies.

\section{INTRODUÇÃO}

O contexto educacional atual clama por novas possibilidades de ação docente, pois é comum o discurso do baixo desempenho dos estudantes nas Ciências da Natureza, em particular na Física, e na Matemática. Muito se ouve que esse fato ocorre devido ao uso inadequado de recursos didáticos por parte dos docentes, fazendo com que tais disciplinas sejam rejeitadas por grande parte dos discentes, elevando o percentual de reprovação nessas áreas do conhecimento.

Uma das ações que podem favorecer a melhoria na situação atual do ensino de ciências como Física e Matemática é a ação diferenciada de educadores comprometidos com a mudança, passando por uma reflexão e revisão de suas práticas e pela busca contínua de metodologias ativas, ou seja, situações didáticas que tragam os discentes para o centro do processo de ensino, possibilitando a construção do conhecimento. Miranda (2016) chama esse tipo de situação didática de atividade criativa.

Neste artigo, buscamos investigar procedimentos autênticos relativos aos processos de ensino e aprendizagem, na elaboração de conceitos mediantes as atividades metodológicas inovadoras nas aulas de Física e Matemática. O objeto do estudo é a ação criativa e inovadora de um professor que busca novas perspectivas no campo metodológico. A criatividade é ressaltada através da utilização de elementos da natureza com a finalidade de desenvolver cognitivamente os estudantes.

A pesquisa apresentada é qualitativa e está baseada em uma experiência docente que se mostra também fundamentada em um exemplo de vida. $\mathrm{O}$ sujeito investigado se torna único por sua prática diferenciada, utilizando o elemento natural amazônico para produzir recursos metodológicos significativos para a aprendizagem da Física e Matemática. Através de observações, entrevistas e registros fotográficos e escritos, buscamos analisar quais elementos da natureza são utilizados, de que forma e qual o seu alcance.

Outra perspectiva deste artigo é a valorização do contexto local na produção de recursos didático-metodológicos na busca por uma identidade local no trabalho com situações didáticas. Trabalhos como o de Oliveira (2004), Alcântara (2008), Alcântara e Terán (2010) e Fonseca (2013) têm mostrado que o potencial amazônico é muito rico, podendo ser explorado pedagogicamente no processo de ensino e aprendizagem de diversas áreas do conhecimento. Este trabalho se configura em uma busca por mostrar que temos na floresta, um tesouro inesgotável de possibilidades que possibilitará o surgimento de uma didática amazônica. 
Portanto, o objetivo desta pesquisa é descrever de que forma um docente da rede pública do estado do Amazonas utiliza os elementos naturais para possibilitar aprendizagem dos discentes em áreas do conhecimento como Física e Matemática. É necessário quebrar paradigmas e fazer do professor um articulador entre o aluno e o conhecimento mediante situações didáticas autênticas e ideais, ou seja, atividades que proporcionem aprendizagens ativas via participação dos discentes. A discussão sobre as situações educacionais no contexto amazônico e de como os elementos da floresta podem influenciar na aprendizagem se mostra promissora devido à importância educacional de tais ações. Portanto, entendemos que a investigação proposta será de grande relevância para a melhoria nos processos educacionais de nossa região.

\section{REFERÊNCIAL TEÓRICO}

Em 2006 na aula de inaugural da primeira turma do curo de Pós-Graduação em Educação e Ensino de Ciências na Amazônia, Mestrado Profissional em Ensino de Ciências na Amazônia, vinculado a Universidade do Estado do Amazonas (UEA), o pensador português Boaventura de Souza Santos destacou a necessidade de uma epistemologia do Sul, ou seja, os países sul-americanos deveriam ser criadores de teorias e não somente copiadores dos conhecimentos elaborados por outros, principalmente da América no Norte e Europa.

Na mesma linha de Boaventura, Capra (2006) ressalta que é necessária uma nova maneira de ver o mundo e de pensar as relações, conexões e contexto, contrariando os princípios da ciência e da educação ocidental, ou seja, temos que valorizar e repensar sobre o nosso ambiente tendo em vista os processos educativos. Nesse caso temos, na floresta amazônica, um imenso um imenso tesouro educacional que precisar ser utilizado.

Há que se refletir sobre o conhecimento local e valorizá-lo, mas para isso, devemos repensar sobre o conhecimento e as formas de construção do saber. Nesse contexto devemos olhar para as práticas locais que utilizam a matéria prima da floresta como instrumento metodológico, possibilitando uma reflexão que nem sempre os materiais instrucionais e a didática que vem de fora é melhor e mais adequada que o fazer local.

A valorização e utilização dos elementos da floresta deve proporcionar uma reflexão sobre a importância da floresta no campo educativo, precisamos olhar para a nossa região como uma fábrica de produtos e matéria prima para o desenvolvimento educacional. Ao abordar a importância do lugar no campo pedagógico, Orr (2006) destaca que em geral essa ideia é 
obscura para muitos educadores, porque, em grande parte, são fruto de uma população destituída de lugar, "para a qual os lugares circundantes não são mais do que fontes de alimento, água, sustento, energia, materiais" (p. 120). Para o mesmo autor o conhecimento regional envolve uma reflexão intensiva sobre o meio ambiente; o conhecimento do lugar "tem a intenção de criar hábitos de pensar interdisciplinares, promover a cooperação e dissolver as barreiras entre fatos e valores, passado futuro, natureza e sociedade humana" (ORR, 2006, p. 122).

$\mathrm{Na}$ área da educação em ciências e matemática essa necessidade é clara, pois só conhecendo o contexto amazônico com propriedade, podemos formular uma teoria capaz de colaborar significativamente com o processo de ensino e aprendizagem dos povos da região amazônica. Com a utilização de materiais oriundos da própria floresta podemos construir materiais didáticos relevantes e autênticos para o ensino das Ciências da Natureza e Matemática, possibilitando o surgimento de situações didáticas com características próprias da região amazônica.

O interesse por uma didática amazônica no campo das ciências da natureza e matemática surgiu a partir de trabalhos anteriores que mostraram de forma clara essa valiosa possibilidade. Oliveira (2004) já vislumbrava o trabalho com temas regionais no ensino de geometria. Ela observou que os conhecimentos no campo geométrico poderiam ser construídos a partir das formas e imagens da Amazônia. O seu trabalho mostrou a importância de um trabalho voltado para o contexto Amazônico. Mesmo sendo um trabalho voltado para a formação de professores, entendemos que se trata de uma valiosa contribuição para o que estamos vislumbrando, pois quando uma professora diz que trabalhar geometria com os elementos da floresta e mais interessante e enriquecedor, certamente nos alerta para a importância de tais situações didáticas no ensino.

Outros trabalhos trouxeram uma reflexão nesta linha, ampliando a discussão e aumentando nossa segurança na busca pela didática Amazônica. Fonseca (2013) pesquisou sobre as metodologias usadas nas escolas do campo em Parintins e buscou comprovar que aulas voltadas para um estudo das ciências naturais utilizando recursos didáticos do ambiente natural e virtual possibilita a consolidação dos conhecimentos de Física adquiridos por alunos do $9^{\circ}$ ano do Ensino Fundamental. Alcântara (2008) investigou sobre as possíveis contribuições dos elementos bióticos e abióticos como recursos didáticos para o ensino de ciências, no processo ensino-aprendizagem na Amazônia em escolas localizadas na zona rural do município de Manaus. A obra de Alcântara e Terán (2010) vislumbra um trabalho com os elementos naturais 
em espaços não formais de ensino. Os autores relatam dificuldades para encontrar textos que abordam a "Amazônia como laboratório em potencial para o ensino de ciências e, sobretudo literaturas que apontassem "os elementos da floresta" como recurso didático para esse ensino" (p. 13). Todos esses trabalhos mostraram uma necessidade e possibilidade de repensar o contexto amazônico em relação as questões didáticas.

Para D'Amore (2007) o conhecimento que um sujeito pode ter sobre um determinado saber Matemático depende das circunstâncias nas quais teve a oportunidade de utilizá-lo, sendo esse um axioma da didática que ainda não foi contradito. Essa ideia pode ser estendida para as ciências da natureza e a Matemática, logo há uma responsabilidade docente a ser considerada, ou seja, como podemos organizar melhor a matéria do ensino, a fim de facilitar a aprendizagem significativa dos alunos?

Na perspectiva de Chevallard (2001) ao ensinar o docente deve refletir sobre a seguinte questão: dado um conhecimento (conceito) que se quer ensinar e dados certos alunos com certas competências, que vivem em um determinado meio, é possível encontrar ou inventar situações cujo estudo permita que eles avancem de maneira eficaz e segura no estudo do conteúdo proposto? Refazendo essa pergunta, é possível elaborar atividades de ensino criativas tendo em vista o contexto amazônico?

Entendemos que as atividades autênticas têm origem nas práticas reflexivas de docentes que de forma criativa usam os elementos da floresta como matéria prima para a criação de materiais didáticos significativos. Outra forma de observar ações no contexto Amazônico diz respeito à utilização de elementos e estruturas culturais como a construção de uma canoa, a confecção de pipas ou a confecção de uma flecha. O objetivo é buscar práticas locais capazes de mostrar uma identidade Amazônica.

A didática postula que para modificar o rendimento dos alunos o fator decisivo é a conduta docente e que esta, por sua vez, pode ser explicada em função do pensamento do professor nos quais estão incluídas suas expectativas, sua maneira de conceber o ensino e aprendizagem e sua forma mais ou menos espontânea de interpretar o saber matemático. Portanto, mesmo sabendo que há vários atores envolvidos no processo educacional, a didática foca a ação docente como elemento essencial para os processos de aprendizagem.

O tripé conceitos, procedimentos e atitudes precisam ser apreendidos, aplicados e desenvolvidos na vida educacional. $\mathrm{O}$ uso de metodologias oriundas de materiais da floresta promove esse desenvolvimento triplo, pois procedimentos e atitudes são desenvolvidos tendo como base a sustentabilidade amazônica e a necessidade de uma pedagogia crítica que reflita 
sobre a região, que alcance os menos favorecidos e proporcione novos horizontes em relação ao desenvolvimento pessoal e profissional.

Para que a atividade instrucional seja efetiva Freitas (2002) destaca que ela deve cumprir duas condições inseparáveis: a situação deve poder ser elaborada com materiais pertencentes ao meio cultural dos alunos, isto é, ao conjunto de objetos cujas propriedades são mais ou menos conhecidas e que podem ser manipuladas de forma suficientemente segura e também, deve possibilitar a geração de algumas questões que dão origem à obra que se quer estudar. Isso significa que, mediante essa pequena variação de certas tarefas e questões conhecidas pelos alunos, deve ser possível provocar o aparecimento dos principais tipos de problemas e técnicas que compõem o conceito em questão.

Ter um conhecimento científico e matemático não é somente saber definições, fórmulas e teoremas para reconhecer o momento de utilizá-los e aplicá-los, contudo, é dedicar-se aos problemas em um sentido amplo, que inclui encontrar boas perguntas assim como encontrar soluções. Uma boa reprodução da atividade científica e matemática, por parte do aluno, exige que este intervenha nessa atividade, o que significa que ele deve formular enunciados, provar proposições, construir modelos, linguagens, conceitos e teorias, colocá-los à prova e realizar intercâmbio com os outros, reconhecer os que estão de acordo com as ideias da ciência e da matemática e considerar aqueles que são úteis para a continuidade de sua atividade.

Na sociedade moderna atual as pessoas precisam desenvolver competências científicas e tecnológicas para resolver os problemas postos pela sociedade, neste sentido, a educação científica é considerada, segundo Cachapuz et al. (2005, p. 20) "um imperativo estratégico" para que a população tome consciência das relações complexas entre ciência e sociedade, possibilitando posicionamentos críticos e tomada de decisões.

Para Delizoicov et al. (2002) há alguns desafios que o professor deve enfrentar, ao ser o porta-voz de conhecimentos científicos e significativos que são: trazer para a sala de aula o mundo em que vivemos, mediar as demandas afetivas e cognitivas, e que possibilitem uma forma de conquista pessoal e coletiva de uma vida melhor. Nesses momentos pedagógicos, distinguem-se três itens com funções específicas que são; a problematização inicial, em que são apresentadas situações reais conhecidas dos alunos, presenciadas e envolvidas nos temas; organização do conhecimento, em que os conhecimentos selecionados são necessários para a compreensão dos temas e da problematização e aplicação do conhecimento destinado a abordar sistematicamente o conhecimento que está sendo incorporado pelo aluno, ou seja, capacitá-lo 
ao emprego dos conhecimentos, no intuito de levá-lo a articularem constante e rotineiramente a conceituação científica com situações reais.

Vale ressaltar que hoje ainda se mantém a velha prática da ciência ensinada, basicamente, transmitindo-se os conhecimentos científicos já elaborados, sem permitir aos estudantes a compreensão e aplicação dos conceitos. No contexto amazônico, as questões relevantes precisam ser discutidas para e problematizadas para que não haja visões distorcidas das áreas do conhecimento, criando desinteresse e constituindo-se em obstáculos para o aprendizado dos estudantes.

Faz-se necessário refletir e rever a forma como o ensino de Ciências e Matemática tem efetivado em nossa região. Cachapuz et al. (2005) dizem que modificar a forma como os professores veem e ensinam Ciências é condição necessária para otimizar a educação cientifica, numa proposta que integre os aspectos conceituais, procedimentais e axiológicos. Desta forma, conhecimento, processos e práticas estarão juntos, tornando as aulas mais dinâmicas e desafiadoras.

Ressaltamos que nesse texto trabalharemos com as questões referentes às atividades criativas do contexto amazônico, que proporcione ao estudante a construção de habilidades para assegurar autonomia na busca pelo desenvolvimento cognitivo e reflexão sobre a região Amazônica. Daremos ênfase às atividades desenvolvidas a partir dos elementos da floresta e as possibilidades que os mesmos podem oferecer para os discentes em relação à educação científica e matemática.

\section{METODOLOGIA}

O trabalho de assessor técnico que realizamos na Secretaria Estadual de Educação e Qualidade do Ensino (SEDUC/AM) e de professor da Universidade do Estado do Amazonas (UEA) nos possibilita mapear as escolas nas quais há trabalhos autênticos e diferenciados que podem ser objetos de investigação tanto na capital como no interior do estado. Sabemos que há um verdadeiro tesouro de ações desenvolvidas em diferentes escolas e que devem ser investigadas, analisadas, discutidas e divulgadas, para que possamos mostrar que temos ações próprias e que podemos criar e desenvolver metodologias próprias no contexto amazônico.

A pesquisa apresentada nesse texto foi realizada no contexto amazônico, com um profissional que trabalha em uma escola do estado do Amazonas e que desenvolve atividades criativas, valorizando o meio ambiente com foco nos elementos da floresta. Entendemos que 
há uma extensa gama de elementos naturais capazes de proporcionar ação, interação e aprendizagem nas Ciências da Natureza e Matemática. O foco será na forma que os recursos são utilizados e nas possibilidades instrucionais geradas, logo não delimitaremos a pesquisa nesse ou naquele segmento de ensino, mas no alcance de tais práticas seja nos anos iniciais, finais ou ensino médio.

A abordagem pensada para o desenvolvimento desse estudo é de cunho qualitativo, pois, de certa forma, está voltada para a compreensão da conduta humana através das ações dos sujeitos. A intenção é descrever as ações educativas de um docente com elementos da natureza e analisar a viabilização desta metodologia para o ensino das ciências naturais e da Matemática. Além da descrição, a análise e interpretação serão desenvolvidas, tendo em vista colocar em relevo a ação única de um profissional da educação. A unicidade e autenticidade do caso estudado justifica sua escolha. As técnicas usadas para coleta de dados nesta pesquisa foram a entrevista, observação, e registros fotográficos realizados durante a entrevista.

Devido à informalidade das interações com o entrevistado, a entrevista realizada foi semiestruturada. Segundo Mazucato (2018) este tipo de entrevista possibilita aos entrevistados respostas e argumentações amplas, ou seja, em qualquer sentido que considere adequada em relação à arguição ou ao estímulo feito pelo pesquisador. Tivemos ampla liberdade para conduzir a entrevista, explorando de forma abrangente temas que consideramos relevantes para a pesquisa, proporcionando uma maior aproximação entre pesquisador e pesquisado, essa interação possibilitou vínculos profícuos com o objeto de pesquisa estudado.

Segundo Lakatos e Marconi (2003) a entrevista é um encontro entre duas pessoas, a fim de que uma delas obtenha informações a respeito de determinado assunto, mediante uma conversação de natureza profissional. Sobre a entrevista não estruturada Mazucato ressalta que:

\footnotetext{
As perguntas [...] devem ser abertas, permitindo assim, uma livre resposta, não limitada por alternativas apresentadas. Sendo livre a resposta, deve-se destacar, os entrevistados possuem total liberdade para questionar as perguntas, a finalidade das mesmas, o desígnio da pesquisa e os motivos de o entrevistado estar indagando sobre alguns temas e questões específicas $(2018$, p. 71$)$.
}

As questões seguiram um roteiro que enfatizavam a idade, formação, tempo de experiência na escola pública, sobre sua prática e a relação desta com a aprendizagem discente. Outro aspecto abordado no diálogo foi sobre a motivação e origem de sua ação diferenciada. A entrevista pareceu mais com um diálogo informal. Segundo Bourdieu (2007) a entrevista 
deveria ser considerada um exercício espiritual, um momento prazeroso, onde o pesquisador consegue suas respostas de forma espontânea e não extorquidas.

Vale ressaltar que a entrevista ocorreu no período de recesso escolar, portanto, na casa do professor. Foi em sua residência que ocorreu a entrevista, observação e registros fotográficos. Em relação à observação Vianna (2003) destaca que não basta simplesmente olhar, mas deve-se saber ver, identificar e descrever diversos tipos de interações e processos humanos. O observar, segundo Mazucato (2018), atrela-se ao estabelecimento de uma percepção atenta; ou seja, não é apenas ver e ouvir, mas também examinar detalhadamente os fatos ou os objetos que se deseja estudar.

O sujeito, cuja a ação será descrita nesse estudo, é um docente efetivo da rede pública estadual há mais de 20 anos e trabalha em uma escola da Zona Leste de Manaus. É um professor participativo e ativo nas atividades formativas realizadas pelo Centro de Formação Profissional Pe. José Anchieta (CEPAN); e em um desses encontro tivemos o privilégio de conhecer a sua prática através de um relato. A partir de então marcamos uma entrevista em sua residência, por ser período de recesso, para conhecer melhor essa prática e divulgá-la. O que vimos nos deixou entusiasmados de tal forma que não poderíamos deixar de relatar o que vimos e ouvimos.

Após os registros realizados durante a entrevista, observação e fotos, passamos para a análise e interpretação dos dados. Escolhemos a análise de conteúdo pois, segundo Gerhardt e Silveira (2009) é uma das possibilidades para a análise do material qualitativo. Das várias possibilidades sobre a análise de conteúdo, escolhemos a análise temática que "trabalha com a noção de tema, o qual está ligado a uma afirmação a respeito de determinado assunto" (GERHARDT E SILVEIRA, 2009, p. 84). Nos registros deste estudo procuramos apresentar de forma fidedigna todas às nuances e percepções vislumbradas nessa pesquisa que foi muito exitosa para nós. Procuramos descrever com clareza e objetividade as inferências realizadas a partir dos registros obtidos. As abordagens observadas foram categorizadas mostrando uma tríade de utilidade do material oriundo da natureza.

\section{ANÁLISES E RESULTADOS}

A pesquisa desenvolvida mostrou que as ações do professor colaborador passam pela utilização de sementes diversas e uma planta abundante em toda a região amazônica chamada buriti (Mauritia flexuosa). Para Sampaio (2012) o buriti é uma das plantas importantes no contexto amazônico e devido a sua diversidade e uso tornou-a conhecida como a "Árvore da 
Vida". Além de fornecer matéria-prima para remédios, alimento, artesanato e abrigo, o buriti desempenha um papel importante para a manutenção de nascentes e cursos d'água, sendo assim fundamental para o ecossistema e para as populações que nele vivem.

Para Sampaio (2012) os principais componentes da folha são a capemba (bainha), talo (pecíolo) e palha (limbo foliar). A capemba é a parte que fixa a folha no caule. O talo tem até $10 \mathrm{~cm}$ de largura, é encoberto por uma fibra dura, conhecida como tala, e é preenchida por um tecido esponjoso, a bucha, que é a medula do talo, semelhante a um isopor. Essa bucha esponjosa é utilizada pelo docente na maioria de suas construções metodológicas.

Sobre as motivações que levaram o docente a tal prática, ele destacou que inicialmente precisava encontrar um material que substituísse a madeira na construção de um jogo, pois a madeira demandava contratar os serviços de um marceneiro, para cortar, lixar e furar. Isso gerava um custo, logo, disse ele, "eu precisava encontrar um elemento alternativo". Depois de pensar, lembrou-se da bucha do buriti, começou a usá-la, daí em diante outras ideias foram surgindo. Ele usava, também, sementes diversas para jogar alguns jogos que ele chamava jogos abstratos. Esses jogos trabalham com a abstração numérica, pois a partir de cálculos, um jogador poderia obter a vitória com mais facilidade. A partir das observações analisamos que os elementos da floresta eram utilizados de três formas distintas.

Em alguns casos os elementos da floresta utilizados pelo professor serviam meramente como objetos de manipulação. Ou seja, eram utilizados como objetos secundários, em atividades lúdicas, nesse caso, podiam ser substituídos por outros objetos qualquer. Eram manipulados como peças de jogos onde o essencial consiste nas reflexões numéricas e cálculos para chegar a uma estratégia vencedora. Foram observados três tipos de jogos desenvolvidos com sementes. Um jogo chamado círculo curioso jogado com a semente chamada de "olho de boi" (Cupania vernalis). A mesma semente servia para o jogar o "nim", um jogo antigo e de raciocínio. Com caroços de açaí (Euterpe oleracea) ele jogava um jogo de origem africana chamado kalah. Com a bucha do buriti (Mauritia flexuosa) construiu peças para um jogo interessante chamado mattix. Em todos esses jogos as sementes são utilizadas como elementos de manipulação, ou seja, não se configuram em elementos de alcance cognitivo, podendo ser substituídos por pedras, tampas de garrafa pet e etc.

Outra forma de utilização foi como objeto de analogia. O uso de analogias e metáforas no ensino de Ciências é bastante comum; vale ressaltar que no contexto Amazônico mais especificamente na floresta há inúmeros elementos que podem ser usados com tal finalidade. Segundo Lara (2014) a analogia pode ser compreendida como uma comparação de 
similaridades existentes entre as estruturas de dois domínios diferentes com intuito de explicar aquele ainda desconhecido, por meio de outro já familiar que será adotado como referência.

Nesse caso o elemento assume uma representação simbólica do objeto estudado, um caroço de tucumã (Astrocaryum aculeatum) pode servir como representação de uma esfera e ainda ser utilizado na Física no estudo do choque entre corpos. Oliveira (2004) utilizou uma vitória régia (Victoria amazônica) como representação de um círculo e a partir dela trabalhou conceitos como comprimento de uma circunferência, área do círculo e etc. Várias folhas, flores e frutos podem ser usados como objeto de analogia na didática amazônica.

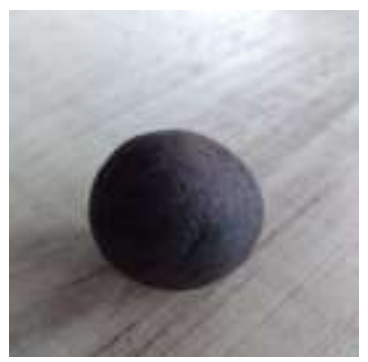

Figura 1: caroço de tucumã usado como analogia de uma esfera

Fonte: os autores (2020).

A terceira forma de utilização dos elementos da floresta que constatamos foi como objeto de construção, nesse caso, podemos notar que o material é utilizado para construir ou confeccionar algum elemento suporte na construção de conceitos matemáticos e físicos. No caso do buriti, podemos construir inúmeros elementos geométricos poliédricos ou não. As talas do buriti são usadas para trabalhar as ideias de retas paralelas e perpendicular. O material do buriti ainda pode ser utilizado na construção de material suporte para trabalhar ideias ligadas a terceira Lei de Newton e ao plano inclinado.

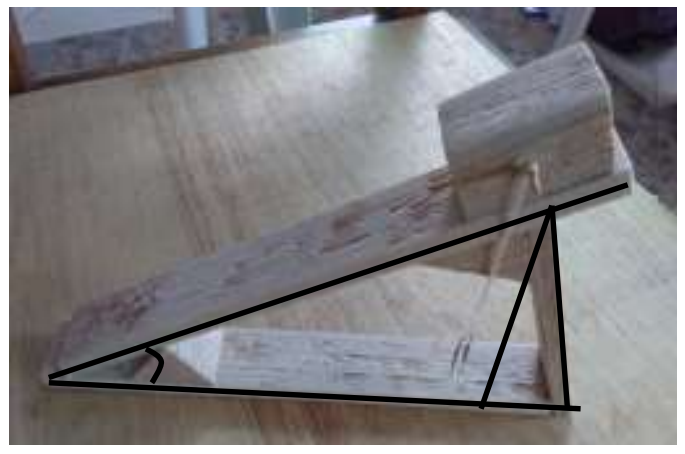

Figura 2: maquete do plano inclinado feita com a bucha do buriti Fonte: os autores (2020).

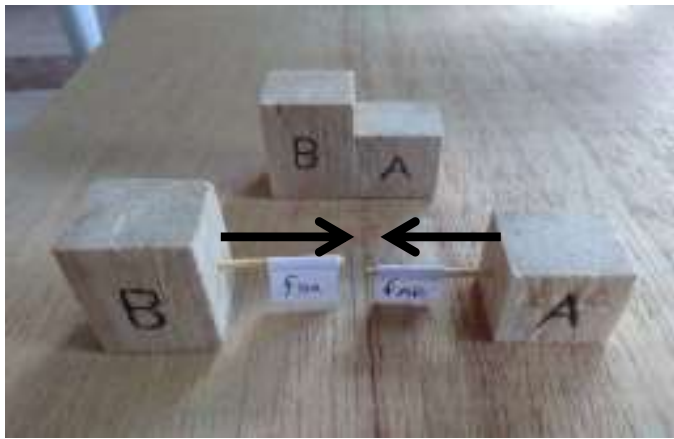

Figura 3: estrutura para trabalhar a $3^{\mathrm{a}}$ Lei de Newton feita com bucha do buriti Fonte: os autores (2020). 
No campo da geometria, percebemos que a bucha do buriti pode ser usada com inúmeras finalidades, a mais clara estava relacionada com as formas tridimensionais. Percebemos que, com o uso de um estilete e de uma lixa adequada, a bucha do buriti pode ser usada e transformada em vários objetos tridimensionais. Prismas, corpos redondos e demais poliedros podem ser construídos e trabalhados de diversas formas. A bucha é um autêntico substituto para a madeira, isopor e outros materiais similares.
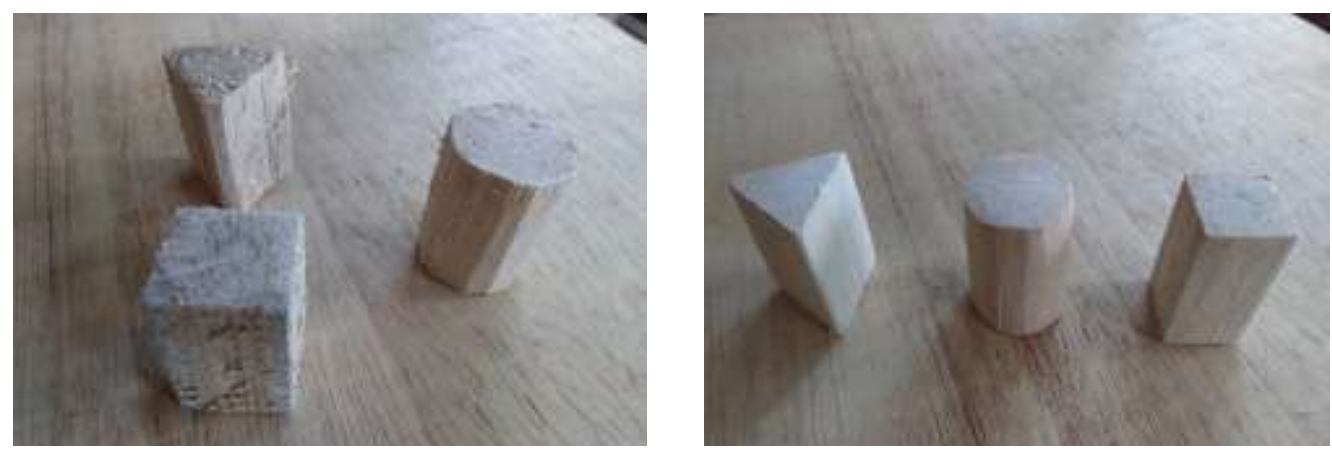

Figura. 4: formas tridimensionais construídas com a bucha do buriti antes e depois de lixadas Fonte: os autores (2020).

Segundo o professor, o material do buritizeiro também pode ser utilizado para a construção de réguas de fração e diversos tipos de quebra-cabeças. Ele diz: "tudo que utiliza madeira, pode ser construído com o uso da bucha do buriti”. O professor ressalta ainda que lhe falta tempo para construir outros materiais instrucionais para o ensino de Matemática e Física. Diz, também, que seguramente, esse material pode ser utilizado nas demais áreas do conhecimento. Os relatos são extraordinários, ele conhece um professor de geografia que usou uma folha para trabalhar o conceito de bacia hidrográfica e afluentes da margem direita e esquerda do rio Amazonas. A espantosa criatividade deste docente só nos dá a certeza de que a busca por uma didática amazônica é possível.

Quando ao nível de aprendizagem dos estudantes o professor ressaltou que os resultados são satisfatórios, pois a partir da manipulação dos objetos concretos a aprendizagem tornou-se mais consistente. Para comprovar o que dissera mostrou uma folha com anotações de uma turma de 42 alunos nas disciplinas Física e Matemática, cujo resultado será mostrado nos quadros abaixo: 


\begin{tabular}{|c|c|c|c|}
\hline & \multicolumn{4}{c|}{ Notas (N) e quantitativos por intervalos - Física } \\
\hline Intervalos & $\mathrm{N} \leq 5,9$ & $6,0 \leq \mathrm{N} \leq 8,9$ & $9,0 \leq \mathrm{N} \leq 10,0$ \\
\hline Quantidade & 07 & 21 & 14 \\
\hline
\end{tabular}

Quadro 1: Quantidade de alunos por intervalos de notas em Física Fonte: Os autores (2020).

\begin{tabular}{|c|c|c|c|}
\hline \multicolumn{4}{|c|}{ Notas (N) e quantitativos por intervalos - Matemática } \\
\hline Intervalos & $\mathrm{N} \leq 5,9$ & $6,0 \leq \mathrm{N} \leq 8,9$ & $9,0 \leq \mathrm{N} \leq 10,0$ \\
\hline Quantidade & 05 & 17 & 20 \\
\hline
\end{tabular}

Quadro 2: Quantidade de alunos por intervalos de notas em Matemática Fonte: elaborada pelos autores (2020).

Para o professor a aprovação de $83 \%$ dos discentes em Física e $88 \%$ em Matemática é digno de comemoração, tendo em vista que essas disciplinas estão entre as que mais reprovam no ensino médio e que antes do trabalho desenvolvido os resultados eram desastrosos, uma vez que os índices de aprovação nestas matérias não passavam de $25 \%$. Ele considera que está no caminho certo e que os estudantes estão compreendendo os conteúdos estudados.

\section{CONSIDERAÇÕES}

Este estudo nos mostrou que as reflexões de Boaventura de Souza Santos são passiveis de ser colocadas em prática em nossa região. Inúmeras são as possibilidades de utilização dos elementos da floresta para o ensino de Ciências Naturais e Matemática. Temos em nossa floresta a matéria prima que pode trazer novos olhares e reflexões no campo da didática. É possível a construção não somente de objetos metodológicos, mas de novas possibilidades no campo científico e educacional no contexto amazônico.

Seja como elemento de manipulação, objeto de analogia, ou seja, como matéria prima de construção, os elementos da floresta podem suprir a carência das escolas em relação aos materiais didáticos instrucionais. Há inúmeros materiais que são comprados pelas secretarias que poderiam servir de complemento para a práxis do educador; ressaltamos que os objetos ligados ao contexto local são mais significativos para os discentes. A bucha do buriti mostrouse efetiva na construção de recursos metodológicos para o ensino de Ciências e Matemática.

Se queremos novos paradigmas no campo científico, devemos começar a olhar, aceitar e valorizar nossa região como promotora não somente de alimentos, madeira, remédios, cosméticos, etc., mas também, de aprendizagem. A natureza sempre foi fonte de ensino, devemos aceitar e buscar práticas que valorizem ações diferenciadas e autênticas. Há outros que utilizam elementos da floresta diferentes dos pesquisados neste artigo. Certamente 
estaremos em busca de tais trabalho e, através de pesquisa, construiremos, pouco a pouco, a nossa didática; uma didática amazônica das ciências.

\section{AGRADECIMENTOS}

Finalizamos esse texto agradecendo ao professor da rede estadual que gentilmente aceitou socializar suas ideias e experiências conosco para mostrar que há muitas possibilidades para o ensino de Ciências e Matemática no contexto amazônico, valorizando o nosso espaço e cultura. Agradecemos também ao professor Yuri Expósito Nicot pela orientação e auxílio na organização e estruturação desta pesquisa e construção desse texto.

Entendemos que essa pesquisa é um caminho que mostrará inúmeras possibilidades para o ensino de Ciências e Matemática na região amazônica. A floresta precisa ser vista não só como um lugar onde vivem os amazônidas, mas um enorme laboratório de possibilidades para os processos de ensino em nossa região. Portanto, devemos um agradecimento especial a floresta amazônica, um ser vivo e eficaz para a educação na Amazônia.

\section{REFERÊNCIAS}

ALCÂNTARA, M. I. Elementos da floresta e ensino de ciências na Amazônia: proposta metodológica para ensinar ciências na área rural amazônica. 2008. 138 f. Dissertação (Mestrado) - Universidade do Estado do Amazonas, Programa de Pós-Graduação em Educação e Ensino de Ciências na Amazônia, Manaus, 2008. Disponível em: http://www.pos.uea.edu.br/data/area/titulado/download/10-21. Acesso em 28 jan. 2019.

\section{ALCÂNTARA, M. I; TERÁN, A. F. Elementos da floresta: recursos didáticos para o} ensino de ciências na área rural amazônica. Manaus: UEA, 2010.

BOURDIEU, Pierre. A Miséria do Mundo. Petrópolis/RJ: Vozes, 2007.

CACHAPUZ, A.; GIL-PEREZ, D.; CARVALHO, A. M.; PRAIA, J. J.; VILCHES, A. (Org.). A necessária renovação do ensino das ciências. São Paulo: Cortez, 2005.

CAPRA, F. Falando a linguagem da natureza: princípios da sustentabilidade. In: STONE, M. K. BARLOW, Z. (Org.). Alfabetização ecológica: a educação das crianças para um mundo sustentável. Tradução Carmen Fisher. São Paulo: Cultrix, 2006. p. 47-58

CHEVALLARD, Yves; BOSCH, Marianna; GASCÓN, Josep. Estudar matemáticas: o elo perdido entre o ensino e a aprendizagem. Porto Alegre: Artmed, 2001.

D’AMORE, Bruno. Epistemologia, Didática da Matemática e Práticas de Ensino. Boletim de Educação Matemática. São Paulo, v. 20, n 28, pp. 179 - 205, 2007. ISSN: 0103-636X. 
Disponível em:

http://www.dm.unibo.it/rsddm/it/articoli/damore/635\%20\%20Epistemologia\%20Didattica.

Acesso em 29 jan. 2019.

DELIZOICOV, Demétrio; ANGOTTI, José A; PERNAMBUCO, Marta M. Ensino de Ciências: fundamentos e métodos. São Paulo: Cortez, 2002.

FONSECA, M. A. O Ensino de física utilizando elementos naturais como recurso pedagógico e laboratórios virtuais no $9^{\circ}$ ano do ensino fundamental na gleba de vila amazônia, Parintins - Amazonas. 2013. 92 f. Dissertação (Mestrado) - Universidade do Estado do Amazonas, Programa de Pós-Graduação em Educação e Ensino de Ciências na Amazônia, Manaus, 2013. Disponível em: http://www.pos.uea.edu.br/data/area/titulado/download/36-13. Acesso em 28 jan. 2019.

FREITAS, José L. Situações didáticas. In: FRANCHI, Anna; SILVA, Benedito Antônio; FREITAS, José Luiz; PAIS, Luiz Carlos; MARANHÃO, Maria Cristina; DAMM, Regina Flemming; IGLIORI, Sonia Barbosa; MACHADO, Silvia Dias. Educação matemática: uma introdução. 2. ed. São Paulo: EDUC, 2002. (série trilhas). p. 65-88

GERHARDT, Tatiana Engel; SILVEIRA, Denise Tolfo. (orgs.). Métodos de pesquisa. Porto Alegre: Editora da UFRGS, 2009.

LAKATOS, Eva Maria; MARCONI, Marina de Andrade. Fundamentos de metodologia científica. 5. ed. São Paulo: Atlas 2003.

LARA, M. S. Elaboração de significados com analogias em atividades na sala de aula de química. 2014. 228 f. Dissertação (Mestrado) - Universidade Federal do Paraná, Setor de Ciências Exatas, Programa de Pós-Graduação em Educação em Ciências e Matemática, Curitiba, 2014. Disponível em: http://www.exatas.ufpr.br/portal/ppgecm/wpcontent/uploads/sites/27/2016/03/030. Acesso em: 28 jan. 2019.

MAZUKATO, T. (Org.). Metodologia da pesquisa e do trabalho científico. Penápolis: FUNEPE, 2018.

MIRANDA, Simão. Estratégias didáticas para aulas criativas. Campinas, SP: Papirus, 2016.

OLIVEIRA, S. Temas regionais em atividades de geometria: uma proposta na formação continuada de professores de Manaus. 2004. 173 f. Dissertação (Mestrado) - Universidade Estadual Paulista (UNESP), Programa de Pós-Graduação em Educação Matemática, São Paulo, 2004.

ORR, D. Lugar e pedagogia. In: STONE, M. K. BARLOW, Z. (Org.). Alfabetização ecológica: a educação das crianças para um mundo sustentável. Tradução Carmen Fisher. São Paulo: Cultrix, 2006. p. 117-126

SAMPAIO, Maurício. Manual tecnológico de aproveitamento integral do fruto e da folha do buriti (Mauritia flexuosa). Brasília - DF: Instituto Sociedade, População e Natureza (ISPN), 2012.

VIANNA, Heraldo. Pesquisa em educação: a observação. Brasília: Plano Editora, 2003. 
Submetido em: 08 de abril de 2020 .

Aprovado em: 18 de julho de 2020. 